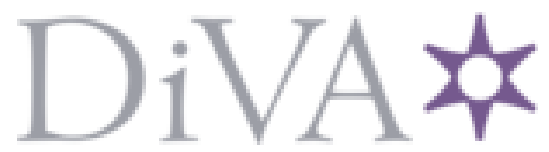

http://www.diva-portal.org

This is the published version of a paper published in Journal of Addiction Research \& Therapy.

Citation for the original published paper (version of record):

Andersson, M., Kjellgren, A. (2016)

Aspects of Substance displacement - from illicit drugs to novel psychoactive substance.

Journal of Addiction Research \& Therapy, 7(3)

https://doi.org/10.4172/2155-6105.1000283

Access to the published version may require subscription.

N.B. When citing this work, cite the original published paper.

Permanent link to this version:

http://urn.kb.se/resolve?urn=urn:nbn:se:kau:diva-45336 


\title{
Aspects of Substance Displacement - From Illicit Drugs to Novel Psychoactive Substances
}

\section{Andersson Martin and Kjellgren Anette ${ }^{*}$}

Karlstad University, Department of Psychology, SE-651 88 Karlstad, Sweden

*Corresponding author: Kjellgren Anette, Professor, Department of Psychology, Karlstad University, SE-651 88 Karlstad, Sweden, Tel: 46547002173 ; E-mail: Anette.Kjellgren@kau.se

Received date: April 12, 2016; Accepted date: June 9, 2016; Published date: June 16, 2016

Copyright: (C) 2016 Martin A, et al. This is an open-access article distributed under the terms of the Creative Commons Attribution License, which permits unrestricted use, distribution, and reproduction in any medium, provided the original author and source are credited.

\begin{abstract}
Several hundred new synthetic drugs, novel psychoactive substances (NPS) or "legal highs" have in recent years appeared on the drug market. These can effortlessly be obtained from on-line vendors, offering an easy access to a plethora of new and untested substances, often with unknown or dangerous effects. Several different attempts to reduce the availability of NPS and to prevent accidents and fatalities have been applied by governments around the world. Nonetheless this complex and constantly evolving situation provides palpable dilemmas and challenges to legislators and prevention strategists. One unintended consequence from prohibition and current drug policies occurs when possibly more precarious substances are used to substitute older and more well-known illicit drugs; so called "substance displacement". We have performed extensive research on the use of NPS, by analyzing Internet resources (drug discussion forum, on-line questionnaires), and published several NPS studies. During our research we observed how substance displacement is a common issue, with implications for both clinical practices, drug prevention strategies, as well as for legislators. In the present review we discuss two common themes of substance displacement: 1) Synthetic cannabinoids replace herbal cannabis, and 2) Different attempts for self-medication using NPS. Incitements for substance displacement, that exposes the user to possibly more harmful substances, are founded both in legislation (availability of substances and fear of legal repercussions) as well as from certain policies or cultural perceptions of various medical conditions. We offer no obvious solutions to these complications, but would like to contribute to awareness of how these factors effects drug users and how measures intended to reduce harm in many cases have the opposite effects. Further studies on the divergent motivations and different groups of NPS users are highlighted as imperative to find new and realistic solutions going forward.
\end{abstract}

Keywords: Substance displacement; Novel psychoactive substances; Legal highs; Drug abuse; Addiction

\section{Introduction}

The increasing supply of novel psychoactive substances (NPS) is changing the drug market in a fundamental way. In 2014, 101 new substances were identified and over 450 new psychoactive drugs are currently being monitored by the European Monitoring Centre for Drugs and Drug Addiction (EMCDDA) [1].

From our on-line studies of NPS and the motivations for using them we have noticed how NPS users have been gravitating towards these new and untested substances as a substitute to illicit substances. Recurrently it was observed that participants in our NPS studies rather would have used a more well-known psychoactive drug (and therefore also illicit) but to avoid consequences and conditions springing from drug prohibition and existing drug policies, often times "settled" for an NPS as a substitute [2-4].

The process where more unknown drugs, with less stringent controls, are used as a substitute to illicit drugs have been referred to as substance displacement by United Nations Office on Drugs and Crime (UNODC) [5]. Substance displacement is listed by UNODC alongside several other unintended consequences from prohibition and current drug policies effecting drug use as well as allocation of limited prevention resources. From our research we have recognized several pathways of NPS use confirming UNODCS accounts, and we have also identified additional factors, like healthcare policies, driving certain types of drug displacement involving NPS. The paradoxical situation of how repressive drug policy tactics contribute to the use of NPS has also been discussed by several other NPS researchers [e.g. 6,7].

Despite the uncharted properties of novel psychoactive substances, participants in our recent study of motivations for using NPS [2] commonly perceived (certain-) NPS as altogether the safest alternative, weighing in the perceived safety benefits provided by the semi legality and the "grey market". An illustrative statement from participants was: "An important reason to choose NPS is that the perceived risk of legal trouble from using illicit drugs is far greater than the perceived risk of serious health issues resulting from occasional research chemical use". Since the supply chain for NPS generally differs from drugs on the black market, the purity of substances and reliability of purchases was perceived as much higher by most of the NPS users [2]. Accordingly, gauging and dosing was also viewed as easier and safer compared to drugs from the black market. Furthermore the NPS users articulated that they much preferred to avoid interactions with illegal drug dealers. The comfort of purchasing substances via internet is a very attractive means of acquisition and is commonly viewed as a much safer alternative than any type of black market dealings.

Besides the downright safety aspects, the mere availability of NPS, or unavailability of certain classified substances, also made NPS users substitute their preferred (illicit) drug of choice with what they believed would be the closest equivalent from the unclassified NPS $[2-4,8]$. In some cases this "displacement" might not be to greater harm 
for the drug user, but we have identified some recurring patterns of substance displacement where possibly much more harmful substances replace more benign and well known substances. Amongst the examples of displacement putting the drug users to greater risk there is two that stands out as particularly prevalent and concerning.

\section{Synthetic cannabinoids substituting herbal cannabis}

From our study of acute poisoning cases at emergency rooms in Sweden it is clear that the synthetic cannabinoids are the culprit of most of the poisoning cases involving NPS [9]. The synthetic cannabinoids and blends such as "Spice" or "K2" were also regularly regarded as especially precarious and were mostly avoided by NPS users in our recent study on motivations [2]. But despite having very bad experiences and viewing the synthetic cannabinoids as much more harmful and addictive than herbal cannabis, there were several examples of participants in the studies $[2,10,11]$ that had been using the synthetic cannabinoids explicitly to avoid positive drug tests and legal repercussions. Participants substituting herbal cannabis with synthetic cannabinoids were apprehensive about legal corollaries like losing their driver's license and attaining a criminal record hindering future employment, even more so than the obvious penalty or immediate risk of incarceration. We observed that this particular substance displacement commonly was disclosed by participants from countries where personal consumption is criminalized (e.g. Sweden), allowing authorities to require a drug test from anyone perceived as under the influence. Displacement of herbal cannabis with synthetic cannabinoids were otherwise mostly described by NPS users currently released on probation, or subjected to similar measures from the criminal justice system or drug testing by an employer. Furthermore, we observed that displacement with synthetic cannabinoids was effectively not at all recounted where herbal cannabis was accepted and readily available. Rolles [6] points out that in the Netherlands, were cannabis is de-facto legal, there is negligible demand for synthetic cannabinoids which supports this contention of substance displacement in the case of synthetic cannabinoid use.

\section{NPS as self-medication}

There is also a type of substance displacement where certain NPS (mainly opiates, stimulants and depressants) replace what otherwise could possibly have been prescribed and monitored by medical personnel. From our studies of motivations for using NPS, there is a considerable group of NPS users defining their use as self-medication $[2,8]$. Many of which, described that they were not able to receive effective medical prescriptions, and consequently turned to NPS for coping with perceived psychological, neuropsychiatric or physical ailments. Sometimes the given prescription drugs were described as having worse side effects, or where seen as less effective than some NPS. In some cases, the NPS users were trying to handle problems like attention deficit $[2,4]$ or pain, but where denied a prescription for effective medication due to certain polices or circumstances like cultural perception of their particular ailment, background or the type of medication they required. Part of the self-medicating NPS users expressed a strong sentiment of dejection regarding healthcare policies and the type of treatment and reception given by medical personnel in their respective countries. Quite a few gave disheartened statements of how they truly did not want to use untested and unmonitored drugs as self-medication, that they much rather would be able to have a proper prescription and be subject to regular medical check-ups, but did not see any other option at the current time [2]. The reality of NPS use should be actively considered by healthcare providers to avoid possibly harmful interaction effects when prescribing medications to patients with an on-going NPS use. Also prescribing physicians need be aware that certain patients might turn to precarious NPS substances when not receiving effective medication.

\section{Implications}

The choices drug users make about their use can be multiple and complex. With the increasing supply of new psychoactive substances reaching the market, the different motivations and types of drug users are not getting any less diverse. Adding to that the relationship between science and politics, that not always work together conjointly, we have a situation that is far from ideal in regards to harm reduction or prevention. Naturally this deeply irrational scenario, where possibly more harmful substances substitutes more benign drugs, raises questions if current policies bring about the desired outcomes and should be investigated further.

To reduce harm and availability of NPS and to meet the dilemma of the ongoing "cat and mouse play," where new drugs are designed to circumvent new classifications, lawmakers have a constant struggle to keep up with the rapid development of new substances. To manage this escalating situation some countries are considering, or already tried, to impose a "blanket ban" of all possibly psychoactive molecules (and instead have a minimal listing of allowed psychoactive substances; i.e., alcohol, nicotine and caffeine). The Psychoactive Substances Act 2016 in the UK is the most recent example of this approach to the NPS phenomenon [12]. Irrespectively how good the intentions have been to take these policy measures, many new dilemmas and consequences from a "blanket ban" have been addressed by researchers, and The UK Psychoactive Substances Act have been extensively criticized. [6,13,14]. Similar legislations in Ireland and Poland have not managed decrease the NPS use or availability accordingly [15].

Considering that clinical trials seldom exist for new NPS, it is hard to assess their toxicity, addiction potential or general profile; which in turn render policymaking very much an uncertain task and most likely not always based on scientific deliberation. Internet drug discussion forums have proven to be a valuable source for surprisingly accurate research data on NPS when clinical trials are not available [e.g. $8,10,11,16]$. To address this difficult situation, we stress the importance of further studies of the divergent motivations and vastly different groups of drug users. If proper differentiation was made between groups of drug users and different types of drugs and motivations for using them, effective allocation of prevention resources and drug policies could possibly be the best option for reducing harm and to prevent addiction or problematic drug use.

\section{References}

1. EMCDDA (2015) New psychoactive substances in Europe. An update from the EU Early Warning System.

2. Andersson M, Soussan C, Kjellgren A (in preparation)The reasons for using novel psychoactive substances - A qualitative analysis of self-reports among online users'.

3. Kjellgren A, Jonsson K (2013) Methoxetamine (MXE)-A phenomenological study of experiences induced by a "legal high" from the internet. J Psychoactive Drugs 45: 276-286.

4. Soussan C, Kjellgren A (2015) "Chasing the High" - Experiences of Ethylphenidate as described on International Internet Forums. Substance Abuse: Research and Treatment 9: 9-16. 
Citation: Andersson and Kjellgren (2016) Aspects of Substance Displacement - From Illicit Drugs to Novel Psychoactive Substances. J Addict Res Ther 7: 283. doi:10.4172/2155-6105.1000283

Page 3 of 3

5. United Nations Office on Drugs and Crime (UNODC) (2008) World Drug Report. Vienna: UNODC.

6. Rolles S, Kushlick D (2014) Prohibition is a key driver of the new psychoactive substances (NPS) phenomenon. Addiction 109: 1589-1590.

7. Werse B, Morgenstern C (2012) How to handle legal highs? Findings from a German online survey and considerations on drug policy issues. Drugs and Alcohol Today 12: 222-231.

8. Soussan C, Kjellgren A (2016) The users of Novel Psychoactive Substances: Online survey about the characteristics, attitudes and motivations. International Journal of Drug Policy 32: 77-84.

9. Soussan C, Sundström K, Andersson M, Kjellgren A (2015) Poisoning casualties: alcohol, pharmaceuticals or "legal highs"? Cases of poisoning at emergency rooms in the Swedish county Värmland region, 2007-2013. Journal of Community Medicine \& Health Education 5: 386.

10. Soussan C, Kjellgren A (2014) The flip side of "Spice": The adverse effects of synthetic cannabinoids as discussed on a Swedish Internet forum. Nordic Studies on Alcohol and Drugs 31: 207-219.
11. Kjellgren A, Henningsson H, Soussan C (2013) Fascination and social togetherness-Discussions about spice smoking on a Swedish Internet Forum. Substance Abuse: Research and Treatment 7: 191-198.

12. Psychoactive Substances Act (2016).

13. Stevens A, Fortson R, Measham F, Sumnall H (2015) Legally flawed, scientifically problematic, potentially harmful: The UK Psychoactive Substance Bill. Int J Drug Policy 26: 1167-1170.

14. Rosca P, Bauer A, Khawaled R, Kahana E, Goldman K (2015) The recent legal approach to new psycho-active substances regulation in Israel: Does it work? J Civil Legal Sci 4:2.

15. Flash Eurobarometer 401 (2014) Young people and drugs.

16. Soussan C, Kjellgren A (2014) Harm reduction and knowledge exchangea qualitative analysis of drug-related internet discussion forums. Harm Reduct J 11: 25. 